San Jose State University

SJSU ScholarWorks

Master's Theses

Master's Theses and Graduate Research

Spring 2015

\title{
Gender Differences in Stress, Alcohol Consumption, and Cigarette Use among College Students at San José State University
}

Thomas Farleigh

San Jose State University

Follow this and additional works at: https://scholarworks.sjsu.edu/etd_theses

\section{Recommended Citation}

Farleigh, Thomas, "Gender Differences in Stress, Alcohol Consumption, and Cigarette Use among College Students at San José State University" (2015). Master's Theses. 4538.

DOI: https://doi.org/10.31979/etd.he8u-j5sg

https://scholarworks.sjsu.edu/etd_theses/4538

This Thesis is brought to you for free and open access by the Master's Theses and Graduate Research at SJSU ScholarWorks. It has been accepted for inclusion in Master's Theses by an authorized administrator of SJSU ScholarWorks. For more information, please contact scholarworks@sjsu.edu. 
GENDER DIFFERENCES IN STRESS, ALCOHOL CONSUMPTION, AND CIGARETTE USE AMONG COLLEGE STUDENTS AT SAN JOSÉ STATE UNIVERSITY

\author{
A Thesis \\ Presented to \\ The Faculty of the Department of Psychology \\ San José State University \\ In Partial Fulfillment \\ of the Requirement for the Degree \\ Master of Arts
}

by

Thomas Farleigh

May 2015 
C) May 2015

Thomas Farleigh

ALL RIGHTS RESERVED 
The Designated Thesis Committee Approves the Thesis Titled GENDER DIFFERENCES IN STRESS, ALCOHOL CONSUMPTION, AND CIGARETTE USE AMONG COLLEGE STUDENTS AT SAN JOSÉ STATE UNIVERSITY

by

Thomas Farleigh

APPROVED FOR THE DEPARTMENT OF PSYCHOLOGY

SAN JOSÉ STATE UNIVERSITY

May 2015

Dr. Sean Laraway, Committee Chair, Department of Psychology

Dr. Susan Snycerski, Department of Psychology

Laurie Morgan M. A., San José State University Student Health Center 


\begin{abstract}
Gender Differences in Stress, Alcohol Consumption, and Cigarette Use Among College Students at San José State University

by Thomas Farleigh
\end{abstract}

Stress, alcohol consumption, and cigarette use represent three considerable threats to the mental and physical health within this country. Learning more about the prevalence and predictors of these threats in young adults may aid the development of programs to reduce the deleterious effects of these threats as young adult's age. A vast amount of research has been done to examine the possible association between stress and substance use in college students, but given the diversity of college students across the US, more research is needed targeting specific college campuses. This study did so with regard to a sample of students from San José State University (SJSU), in San José, California. The data were collected by the SJSU Student Health Center. Participants who reported having below average to no stress were more likely not to have consumed alcohol during the preceding 30 days. Those students who reported having above average to tremendous stress levels were more likely to have used alcohol at least once in the last 30 days. No significant relationship between stress and cigarette use was found. In terms of alcohol and cigarette use, participants who reported using alcohol at least once in the past 30 days were significantly more likely to have smoked at least once in the past 30 days. Women were more likely to report feelings of above-average stress than to men. Women were also significantly more likely to have smoked cigarettes in the last 30 days. Finally, no gender differences were found with regard to drinking habits. 
These findings provide information that may be helpful in guiding prevention, education, and treatment efforts on the SJSU campus. 
TABLE OF CONTENTS

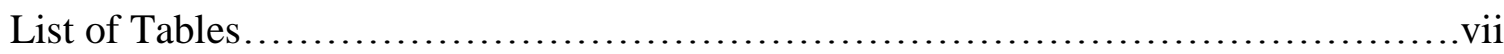

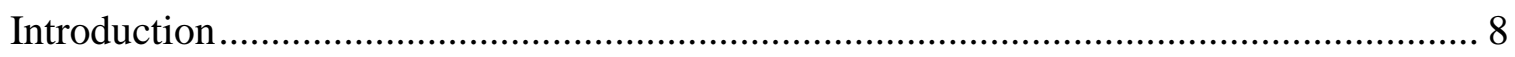

Stress: Physiological and Psychological Effects....................................................... 23

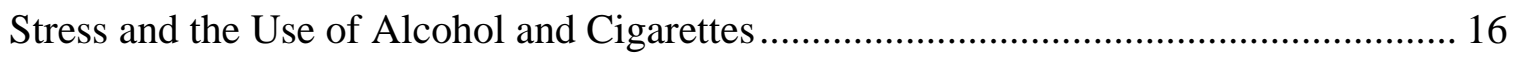

Gender Differences in Stress, Alcohol Use, and Cigarette Smoking ............................. 31

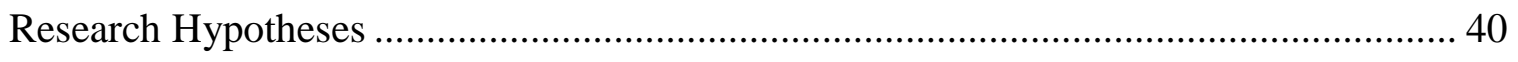

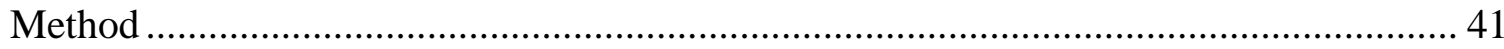

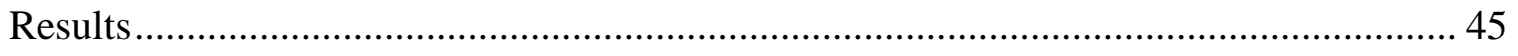

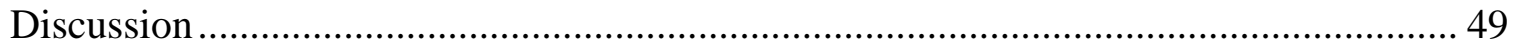

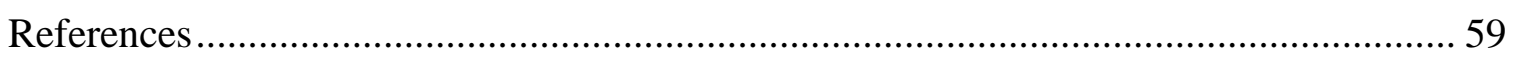

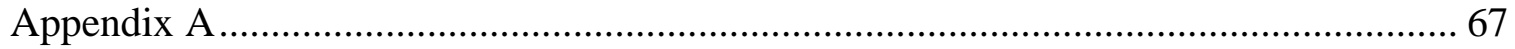

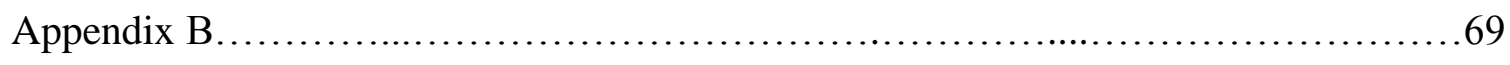




\section{LIST OF TABLES}

Table

1. Frequency distribution of student demographics .................................................43

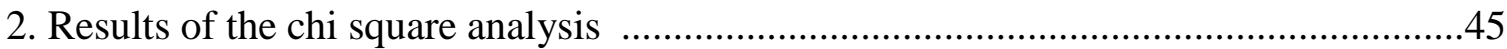

3. Frequency distribution of stress in the past 12 months by frequency of alcohol use in

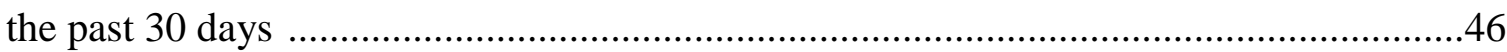

4. Self-reported levels of stress by frequencies of cigarette use in the last 30 days ........46

5. Frequencies of alcohol and cigarette use in the past 30 days ....................................47

6. Self-reported frequencies of stress levels in the last 12 months between genders ......47

7. Self-reported frequencies of alcohol use in the last 30 days between genders ............48

8. Self-reported frequencies of cigarette use in the last 30 days between genders ...........48 


\section{Introduction}

Stress, cigarette and alcohol remain serious issues to the overall health and wellbeing of the people living in the US (Hughes, 2005). College students remain at risk from these three threats to their health. For many students, college life brings a variety of stressors, including those involved in transitioning away from home, academic pressures, and forming new social relationships, and the stress experienced by college students can be severe (Brougham, Zail, Mendoza, \& Miller, 2009). Stress can affect important aspects of college students' daily functioning. For example, stress is one of the primary predictors of poor sleep quality (Lee, Wuertz, Rogers, \& Chen, 2013; Lund, Reider, Whiting, \& Prichard, 2009). Stress is also correlated with smoking in college students (e.g., Naquin \& Gilbert, 1996), but this correlation weakens when controlling for the use

of alcohol and marijuana (Magid, Colder, Stroud, Nichter C. M., \& Nichter J. R., 2009). Although stress is not as a strong of a predictor of cigarette smoking as other variables in college students, students do report that they smoke to cope with stress and negative emotions (Cronk \& Piasecki, 2010; Piasecki, Richardson, \& Smith, 2007). Regardless, cigarette smoking among college students is quite prevalent, with nearly $30 \%$ of college students reporting that they have smoked in the past 30 days (Johnston, O’Malley, \& Bachman, 2003; Patterson, Lerman, Kaufman, Neuner, \& Audrain-McGovern, 2004; Wetter et al., 2004). As with cigarette smoking, the relationship between alcohol use and stress is also complex, with researchers reporting mixed findings in support of the hypothesis that college students use alcohol to cope with stressful events (e.g., Park, Armeli, \& Tennen, 2004; Read, Wood, Kahler, Maddock, \& Palfai, 2003). Nevertheless, 
there is substantial evidence that stress is a factor in substance use and abuse (Herman, 2012).

Effective health-education and intervention programs on college campuses require specific information on the prevalence of health problems, including those resulting from unhealthy lifestyles as well as the characteristics of students who are likely to suffer from health problems. In the present study we examined the relationships among stress, alcohol and cigarette use, and gender in a sample of San José State University students surveyed by the SJSU Student Health Center (SJSU SHC). In this thesis, we describe the findings from this survey and their implications.

\section{Stress: Physiological and Psychological Effects}

In the next few sections, we review the human and nonhuman research on stress and its effects on physiology and psychological processes. Stress in biological and psychological functioning can be traced to the work of Hans Seyle starting in the mid 1930s (Seyle, 1936). Ursin and Eriksen (2004) noted that Seyle's 1936 paper is sometimes credited for first using the term stress in the scientific literature, but the term did not appear in this landmark paper on the subject. Rather, he mentioned a three-stage process that organisms experience when exposed to "nocuous [noxious] agents," such as cold, surgery, or the administration of certain drugs (Seyle, 1936, p. 32). Seyle (1950) later described three stages of what he termed the General Adaptation Syndrome. The first stage is an alarm reaction, which involves the initial behavioral and physiological responses to the presence of some aversive stimulus, called a stressor. In the second stage, the stage of resistance, the organism's body attempts to adapt to the stimulus that 
caused the alarm. For example, the so-called "fight-or-flight" syndrome characterized by sympathetic nervous system (SNS) arousal is an example of one such adaptation. The final stage of exhaustion occurs if the stressor remains present for a long enough period of time and overwhelms the organism's coping systems. This stage may result in illness or even death (Beck, 2004, p. 267). Ursin and Eriksen (2004) described the stress response as "a general alarm in a homeostatic system, producing general and unspecific neurophysiological activation from one level of arousal to more arousal" (p. 567). This reaction is activated when there is some type of imbalance in a homeostatic system due to a physical or psychological event. Although the stress response is adaptive in that it attempts to maintain homeostasis, it can be harmful to the individual when the response is drawn out over an extended period of time (McEwan, 2000; Ursin \& Erikson, 2003).

Although Seyle's work was important in alerting scientists to the importance of stress to biological and psychological functioning, the concept of stress is somewhat ambiguous in that it encompasses a wide variety of definitions and meanings (Koolhaas et al., 2011; McEwan, 2000). For example, the definition of stressor as any stimulus that disturbs homeostasis has led to criticism because most stimuli affect homeostasis in some way or another. Thus, using the homeostatic definition, nearly every stimulus can be considered a stressor, even though we generally think of stressors as aversive or noxious stimuli that organisms seek to avoid. In fact, many rewarding or appetitive events also produce disturbances in homeostasis with physiological effects similar to that observed following aversive events (Buwalda, Scholte, de Boer, Coppens, \& Koolhaas, 2012; Koolhaas et al., 2011; McEwan, 2000). McEwan argued that homeostasis is better used 
for those truly life-maintaining systems like body temperature, which are required for survival but are not used to help the organism adapt to changing environmental conditions. Instead, he proposed that we use the term allostasis to refer to those systems that vary in response to environmental conditions (e.g., changes in hormone release, heart rate).

Because of the ambiguities involved in previous definitions of stress and stressors, researchers have suggested refined definitions of these concepts. For example, McEwan (2000) defined stressors as "events that are interpreted as threatening to an individual which elicit physiological and behavioral responses [to reduce the threats]" (p. 173). Koolhass et al. (2011) and Ursin and Eriksen (2004) proposed that a reasonable definition of stressors should take into account the cognitive (e.g., anticipatory) and perceptual responses to stimuli that overwhelm the organism's ability to cope with the stimulus, particularly when those events are unpredictable and uncontrollable (see Dickerson \& Kemeny, 2004). Thus, in determining whether or not an event qualifies as a stressor, we must understand the individual's perceived threat from that event. In humans this is relatively straightforward, as most verbal humans can describe their internal states. In nonhumans, identifying perceived stress poses some challenges, but it is possible (Koolhaas et al., 2011). The definitions of stressor offered by McEwan and Koolhaas and colleagues have a common theme: the event must be perceived as posing a threat to the psychological or physical wellbeing of the organism. According to these authors, the stress response has physiological, cognitive, behavioral, and emotional components that work to cope with the presence of the stressor. 
The occurrence of a threatening event triggers a cascade of biological and behavioral reactions. Systems located in the central and peripheral nervous systems (CNS and PNS, respectively) respond to stressors by initiating a series of responses. The major system in the PNS responds to threatening events is the sympathetic nervous system (SNS), which is responsible for the flight-or-fight syndrome. This syndrome is characterized by several behavioral and physiological adaptations, including increased attention, suppression of appetite, increased flow of oxygen and nutrients to the brain, and increased respiratory rate, among others (Charmandari, Tsigos, \& Chrousos, 2005). All of the responses physically prepare the organism to avoid or confront the threatening event.

One of the most studied parts of the stress-response system is the hypothalamicpituitary-adrenal (HPA) axis. The HPA axis helps prepare the body for action in response to a variety of events, including stressors. When the stress response is initiated by the detection of a threatening event, the neurons in the paraventricular nuclei (PVN) of the hypothalamus releases corticotrophin-releasing factor (CRF), among other chemicals. CRF then causes the pituitary gland to release adrenocorticotrophin hormone (ACTH), which travels through the bloodstream. Eventually, ACTH reaches the adrenal cortex (located in the adrenal glands on the kidneys), which is responsible for synthesizing and releasing stress hormones (glucocorticoids), particularly cortisol (Herman, 2012). Cortisol, often called the stress hormone, has a variety of biological functions, including mobilizing energy for action and modulating the cardiovascular and immune systems. Cortisol also influences our emotional and cognitive responses to life events (Kudeilka \& 
Kirschbaum, 2005). The release and circulation of cortisol is necessary for normal functioning, but chronic exposure to stressors can induce long-term activation of the HPA and subsequent cortisol release, which is associated with a variety of harmful outcomes, including depressive symptoms, memory problems, immune system suppression, and the development of chronic diseases (Charmandari, Tsigos, \& Chrousos, 2005; Dickerson \& Kemeny, 2004; McEwan, 2000).

Because of ethical issues in conducting experimental chronic stress research in humans, researchers often use animal models to study the harmful effects of chronic exposure to stressors. For example, Chakravarty et al., (2013) examined the impact of chronic stress and its relationship to anxiety in a sample of Zebra fish. The authors noted low levels of stress can have beneficial outcomes in the form of improved memory and awareness, but overexposure to stressors can have deleterious effects including the development of mood disorders, such as anxiety. To test this association between chronic stress and anxiety the researchers exposed fish to a multitude of chronic stressors, including living in an overcrowded tank, restraint, isolation, being chased by other fish, and the novel tank test, which is similar to the elevated plus maze test used to assess anxiety in rodents. The novel tank test divides a tank into three equal horizontal sections by making marks on the outside of the tank. The fish are put in the tank for 2 min and the amount of time the fish stays in one section is measured. The amount of time spent in the bottom two zones is indicative of anxiety in the fish. In addition, the more times a fish freezes in one spot for an extended period is used as a measure of anxiety because freezing is a common defense reaction to threatening stimuli. The Zebra fish that were 
exposed to a chronic stressor exhibited signs of anxiety by their changed patterns of swimming. These fish spent significantly more time freezing in one position compared to fish that were not chronically stressed. The researchers also reported that the stressed fish showed an affinity for the dark areas of the tank, avoided the lit portions, explored less, and displayed unpredictable locomotion when compared to the fish in the control condition. Taken together, prolonged stress led to behavioral symptoms of anxiety in this animal model. For the chronically stressed fish that had shown anxiety-like behavior, Chakravarty et al. (2013) dissected the fish's brains in an effort to assess biological indicators of anxiety. The brains revealed several key biological indicators of anxiety including CRF and decreased neurogenesis in the hippocampus and other brain areas. These findings are an indication that chronic stress, if left unchecked, can lead to harmful outcomes such as anxiety and reduced neuronal growth.

Engelbrecht et al. (2010) investigated the effects of chronic stress on muscle atrophy in adult male rats. The authors noted there is a fine line between the positive and negative effects of stress hormones: "in skeletal muscle, glucocorticoid deficiency leads to debilitating fatigue, myaglia (i.e., muscle pain), and general muscle weakness, whereas excess glucocorticoids causes decreased rates of protein synthesis, excess catabolism, and muscle atrophy" (p. 132). Engelbrecht et al. examined chronic stress in adult male rats by restraining them for two hours a day for 30 consecutive days. Immediately following the study, all of the rats were sacrificed and their skeletal muscle was removed. Rats that experienced chronic stress had significant atrophy in the muscle compared to control rats that did not experience restraint. Chronic stress also led to increased cell death. This 
study provides evidence of the deleterious effects of chronic stress leading to muscle atrophy, which can be debilitating and painful.

Chronic stress may also pose problems for the cardiovascular system. Elliot, Faraday, and Grunberg (2003) examined the effects of stress on the physical structure of the heart and resulting cardiovascular health. The researchers noted that stress can lead to changes in blood concentration, which forces the heart to work harder to pump blood. For humans, this can lead to chronic anxiety, psychological distress, and damage to the cardiovascular system. Elliot et al. subjected male and female adult rats to $20 \mathrm{~min}$ a day of restraint for two consecutive weeks. After the two-week period, they measured heart morphology and total blood volume by analyzing the rats' hearts. Restraint stress led to changes in the rats' blood volume and heart mass. The stress condition increased septal wall thickness and reduced left ventricle width in male rats. Both sexes in the stress condition experienced a decrease in blood volume. In addition, both males and females rats subjected to the stressor weighed less than did the non-stressed rats. The authors suggested that if these findings can be applied to humans, they highlight the importance of how stress can change the physical dimensions of the heart, which could lead to negative outcomes such as heart disease and high blood pressure.

Although the effects of chronic stress on health have been widely publicized, acute stressors can also have deleterious effects. Raio, Orederu, Palazzolo, Shurick, and Phelps (2013) noted that individuals can modify their emotional responses by engaging in cognitive emotional regulation, which involves a concentrated effort to change our emotional responses in order to make better decisions. After an initial reaction to an 
event, the meaning and importance of an event can be changed through various strategies, including reinterpreting the event or focusing on its positive aspects. By doing so, we can lessen the components of the stress response, including the subjective and physiological aspects. Cognitive regulation requires the activity of brain regions involved in higher cognitive functioning, particularly the PFC (prefrontal cortex). However, acute stress can dampen the effects of cognitive regulation by influencing how well the PFC performs. Thus, the area of the brain that is most important for regulating our emotions during times of stress is itself impaired by stressors. Indeed, Raio et al. found that acute stress weakened adult humans' capacity to use cognitive regulation when confronted with a stressor even after the participants were given cognitive regulation training.

With respect to cognitive processes, Andreano and Cahill (2006) noted small amounts of acute stress can improve memory retrieval but large amounts can inhibit this. To further investigate this relationship and possible gender differences in response to acute stressors, the authors studied undergraduate participants. Researchers first read the participants a story, which the researcher's deemed to contain neutral content. Following this, participants either put their hand in a bucket of ice water (i.e., an acute stress condition), a bucket of room temperature water (i.e., a control condition) for three minutes, or until participants stated they no longer wished to continue. Participants' cortisol levels were measured at the start of the protocol and 15 min after the completion of either condition to confirm the stress protocol did in fact create stress in participants. Participants returned to the lab seven days later and were required to tell the story again 
as error-free as possible, with the number of correct responses from each participant recorded. Males who were subjected to the acute stressor recalled twice as many correct events pertaining to the story as those who were not subjected to the stressor. However, there was no significant difference in performance for females between conditions or between both genders in the control conditions. The authors described the results as an inverted U-shaped association between stress and memory retention in men, with stress facilitating memory retention up to a point. Beyond this point stress impaired memory retention.

The cognitive response to stress is an important component in understanding the stress reaction. As we noted above, a stimulus cannot be considered a stressor unless the organism perceives it as a threat, and that most stressors are learned cues that signal danger as a result of a previous experience (i.e., the stress response often involves an organism's anticipation for threatening events due to a specific learning history). Therefore, to understand stress and its effects on health, behavior, and mood, it is necessary to understand how organisms process stress-related stimuli to anticipate threats (Ursin \& Eriksen, 2004). When an individual is subjected to a stressor, the person's interpretation of that stimulus partially determines whether it is positive or negative, and the interpretation is largely based on past occurrences and experiences as well as the context in which the stressor occurs. Of course, some stimuli would almost always be perceived as harmful no matter what the context was, and some stimuli would be seen as helpful in any circumstance (Ursin \& Eriksen, 2004) 
Gaab, Rohleder, Nater, and Elhert (2005) noted that the physical response to stress has been well documented, but the cognitive processes involved in the stress response are less well known. The authors argued that stress is simply the byproduct of a person's "cognitive appraisal" of the situation in which he or she finds him or herself. These appraisals can occur before or after a stressful event (termed anticipatory or retrospective appraisals, respectively). Prior research has mostly examined retrospective appraisals, but such appraisals do not often correlate with HPA axis responses. Therefore, Gaab et al. examine whether or not anticipatory or retrospective cognitive appraisals were associated with the HPA axis stress response. To do so, these researchers measured cognitive appraisals before and after a stressful situation. Participants performed the Trier Social Stress Test (TSST), which is designed to induce social stress by having participants take a mock interview and do arithmetic in their head in front of several strangers. Following the TSST, participants indicated their perceived level of stress and self-control using a visual analog scale (VAS). Gaab et al. also measured salivary cortisol levels immediately after at the completion of the VAS. They found that anticipatory, but not retrospective appraisal was a significant predictor of the stress response. Gaab et al. noted that the "HPA axis has a strong anticipatory component" (p. 607. In other words, the stress response is more strongly tied to perceptions of what might happen, as opposed to what has already occurred (Gaab et al., 2005). This makes sense if we consider that a major function of the stress response is to prepare the organism for upcoming threatening events. Gaab et al. also noted that cognitive- 
behavioral stress management training is effective in changing cognitive appraisal processes, thereby reducing cortisol levels.

These data are consistent with cognitive activation theory of stress (CATS), developed by Ursin and Eriksen (2004) to predict and explain situations in which exposure to stressors would have harmful effects on health. These authors argued that an event an organism perceives as a threat brings forth certain coping strategies to reduce the arousal produced by that threat, with the best strategy being the one that reduces or eliminates the threat. In addition to learning behaviors that avoid or reduce threats, the CATS model proposes that coping involves learning that responses to stressors will be successful. In the words of Ursin and Eriksen, "coping is a positive response outcome expectancy” (p. 576). That is, true coping requires that organisms learn their behavior will effectively reduce the physiological effects of the stressor. This implies that the individual perceives that he or she has some control over the situation. People who report having experienced stress but perceive that they have low levels of control, particularly when they have little social support, are more likely to suffer deleterious effects of stress than are those who perceive that they have high levels of control. As Ursin and Eriksen noted, the sense of control is similar to the concept of perceived self-efficacy, which "is concerned with judgments of how well one can execute courses of action required to deal with prospective situations" (Bandura, 1982, p. 122). The related concepts of perceived control and self-efficacy have important implications for an individual's physical and mental health. In terms of college students, providing opportunities for social support (or emphasizing the importance of social support) and for increased feelings of self-efficacy, 
and control through stress management training can help to buffer them from the negative outcomes of stress.

As we have seen, stressors can create a number of negative outcomes in individuals, and college students face a number of unique stressors, including moving out of the home, facing new academic challenges, trying to finance their education, forming new social relationships (Brougham et al., 2009), and so on. Kelly, Lavergne, Boon Jr., and Boon (2012) reported that of all college students who started at a university as freshmen only $31 \%$ graduate within six years. The researchers noted that students' ability to create or maintain healthy social networks improves their chances of graduating with a degree. In addition, the authors maintained that "social networks provide stability and predictability; by contrast the lack of social support often leads to problems of adjustment and withdrawal" (p. 654). Kelly et al. developed a two part descriptive survey, designed to assess which aspects of students' social lives were most important to their success or failure in college. The most frequently cited positive social factor is students' lives were feeling supported by their family (95\%), having a solid relationship with faculty (90\%), and enjoying their classes pertaining to their major (86\%). In addition, the most noted negative factors included feeling burnt out from their college experience (57\%), an inability to manage their time (52\%), and being unable to cope with their stress (52\%). Again, college students have consistently pointed to stress as a critical component of their ability to adapt to college and all it entails, but having regular positive relationships with their family and professors, may protect them from the rigors and stress of academics. 
Bland, Melton, Welle and Bigham (2012) argued that "Millennials" (young people born after 1982) face some unique challenges as college students. In the near future, this cohort will make up roughly $20 \%$ of the population in the US, and they have more educated and affluent parents than did previous generations of college students. Because of this, these students are "over scheduled and heavily monitored, and pressured to excel academically" (Bland et al., 2012, p. 363). Bland et al. used a cross-sectional study to investigate sources of stress and stress-management strategies in a group of predominantly freshman college students. The students reported the stressful life events they had experienced in the past year. The most frequently reported stressor was pressure to excel in academics, followed by having their living circumstances changed. The daily hassles (occurring in the past month) most noted by students were exams, putting things off, not getting enough sleep, and school assignments. The researchers pointed out these different types of stressful occurrences in a predominantly freshmen sample illustrate how these students are becoming stressed from attempting to accustom themselves to college life. Of the coping strategies assessed, only the feeling of support by family, friends, or teachers was a significant protective factor for tolerating stress. As previous research has found, social support can provide a buffer to stressful events.

Dealing with academics requirements and the substantial cognitive effort involved in earning a degree are some examples of the stressful challenges faced by college students. Many also worry about financial issues. For example, May and Casazza (2012) noted that over $75 \%$ of college students reported experiencing at least modest levels of stress resulting from finances, with $10 \%$ reported experiencing high levels. Nelson, Lust, 
Story, and Elhinger (2008), using a sample of 3,206 college students, reported that 23\% of students were carrying debt in excess of over $\$ 1,000$. Stress and debt were both linked to poor physical health, outcomes such as gaining weight, failing to exercise, watching too much television, eating an improper diet, drinking large quantities of alcohol in one sitting, and using other drugs.

Taking exams is a major part of college, and past studies examining test anxiety have found that the more difficult the content of a test, the higher the level of stress reported by the students. May and Kyle (2007), for example, found that undergraduate engineering and pharmacy majors had higher stress levels than a random sample of undergraduate social science majors. May and Casazza (2012) categorized students by their major and classified the majors as hard (e.g., biology, chemistry) or soft majors (e.g., English) and administered a survey designed to measure stress levels. Students who enrolled in hard majors reported feeling more stress than those students enrolled in soft majors. The authors argued that so-called hard majors often require the individual to absorb a substantial amount of technical information that soft areas do not, thus making the "harder majors" inherently more difficult and stressful to study.

As we have seen, college students face many sources of stress. Unsurprisingly, these stressors take a physical and mental toll on college students. Hughes (2005) argued that stress is a substantial problem for college students, which contributes to poor physical health, such as elevated blood pressure and a weakened immune response. The author also noted that in terms of the psychological effects of stress, it can lead to increases in risky behavior and symptoms of depression, as well as decreases in feelings 
of physical and mental energy and self-esteem. In addition, stress has also been shown to be a contributing factor to the development of anxiety, and college students' anxiety can be detrimental to academic success by diminishing their ability to cope with everyday life stressors in healthy ways. Hughes also pointed out that stress can lead to poor choices related to health by reinforcing immediate gratification (e.g., eating junk food), as opposed to healthy lifestyle habits, such as proper diet and exercise. Finally, the author noted stress can put great deal of strain on an individual's interactions with others, thereby resulting in the weakening of his or her most important relationships. To summarize, stress in college students is a substantial problem that may interfere with their physical, mental, and academic functioning.

\section{Stress and the Use of Alcohol and Cigarettes}

As we have seen, the occurrence of stressors evokes coping behaviors, some of which are adaptive whereas others are maladaptive. One common maladaptive coping strategy is alcohol consumption. Becker, Lopez, and Doremus-Fitzwater (2011) argued that alcohol is known to reduce anxiety, so exposure to stressors may create a drive in certain individuals to drink to reduce their stress. This is known as the "stress-reduction hypothesis" (Becker et al., 2011). Obviously, individual differences must be taken into account. Not everyone who is stressed will turn to alcohol to cope. Indeed, individuals have varying levels of sensitivity to the effects of stress and willingness to use of substances to cope. In terms of alcohol consumption, aspects such as an individual's previous experience with alcohol plays an important role in that person's decision to drink alcohol. Consistent with the research we discussed earlier, Becker et al. noted that 
important factors related to stress include, but are not limited to, the "type, controllability, and predictability" of the stressful stimuli (p. 132). As we have seen before, if a stressor is predictable and seen as being within one's control, the individual will be better prepared to cope effectively with that stressor.

Rutlidge and Sher (2001) examined the relationship between stress and alcohol use in a sample of college students through the lens of the stress-reduction model. To test this model, the researchers conducted a longitudinal study with a sample of 489 college students over a five-year period. At each year, the researchers measured emotional distress and the number of negative life events. Participants were also asked to report how much they drank in the past year and to what extent they felt their alcohol use was motivated to reduce stress. Heavy drinking was significantly related to stress in the fourth year (mean age $=21$ years), and men in this cohort were more likely to have reported a larger number of negative life events, have more heavy alcohol consumption, and an increased motivation to drink to reduce stress levels. This is not surprising given that the fourth year coincided with the participants turning 21 and gaining the legal right to drink alcohol. There were some interesting trends in terms of gender. In the first year, there was no significant difference between men and women in terms of tension reduction and heavy alcohol consumption. However, in the second through fourth years, men reported drinking more heavily to reduce stress levels than did women. In the fifth year, when students were finishing their education, the difference between men and women on drinking to reduce tension was even larger. From these results, we can conclude that many male college students seem to use alcohol to reduce stress levels. 
Although drinking seems to increase across the college years, freshman students occasionally get into trouble with alcohol. O’Hare and Sherrer (2006) examined drinking in freshman using a sample of freshman who had been caught drinking alcohol on campus. Using a survey, the researchers assessed stress and alcohol use in this sample. The researchers noted a majority of these freshmen could be categorized as problem drinkers, and most of the problem drinkers were men. Males who self-reported having higher stress levels were also more likely to be classified as problem drinkers. These men were more likely to report having interpersonal problems and impulsivity. The women problem drinkers reported having stress stemming from problems with concentration. The authors argued that for women, problems with concentration are often associated with anxiety and depression, which is commonly related to the internalization of problems. In contrast, men who have problems with other individuals and issues with impulsivity are thought to be an attempt to externalize their problems. These findings further strengthen the notion that high levels of stress and alcohol use are related to one another in college students in their first year.

As discussed above, stress can have detrimental effects for the physical and psychological wellbeing of individuals, and individuals seek to cope with stress in different ways, one of which is drug use. Tobacco is another drug that can be used to cope with stress, and in naturalistic studies some individuals report smoking more when experiencing stress (e.g., Cronk \& Piasecki, 2010; Piasecki et al., 2007). Laboratory studies have shown that exposure to acute stressors increases the desire to smoke (Perkins \& Grobe, 1992), and smoking following exposure to acute stressors decreases subjective 
feelings of stress, even though doing so increases cardiovascular arousal (Perkins, Grobe, Fonte, \& Breus, 1992). Because stressors increase nicotine self-administration, researchers have suggested that stressors may increase smoking behavior by altering the reinforcing value of nicotine (Lutfy et al., 2006).

Childs and de Wit (2010) suggested an alternative explanation: stressors reduce the psychoactive effects of nicotine, so smokers try to make up for this reduction by increasing their smoking. To test this notion, these researchers studied 17 daily cigarette smokers. Participants were assessed for nicotine dependence and then were assigned to perform the TSST or a control condition. After these conditions, participants were given a smoking-choice procedure in which they could choose to smoke half a cigarette of their favorite brand or receive money. These choices were made every $15 \mathrm{~min}$ and measures were made before and after each choice. The researchers calculated stress levels by collecting salivary cortisol and alpha-amylase (an indication of autonomic nervous system arousal). Using a visual analog system (VAS), participants reported their mood, level of nicotine craving, and enjoyment of smoking. Stress significantly increased participants' reported desire to smoke, but did not increase choices for smoking overall. Participants who reported highly consistent patterns of smoking enjoyed smoking more after being exposed to the stressor than did those who reported less consistent smoking patterns. Thus, being exposed to an acute stressor made smoking more pleasurable for these participants. Participants who reported a stronger urge to relieve withdrawal and craving by smoking also experienced more pleasure from smoking but, unlike other participants, they also smoked more. The researchers noted these findings confirm the 
notion that stress increases an individual's desire to smoke and, following exposure to a stressor, smokers seem to enjoy smoking cigarettes more. A subset of smokers will also increase their smoking in response to stressors. This subset of smokers may be partly responsible for the mixed findings observed in previous survey studies on the relationship between stress and smoking behavior (e.g., Cronk \& Piasecki, 2010; Magid et al., 2009; Piasecki et al., 2007).

With respect to chronic stressors, Ansell, Gu, Tuit, and Sinha (2012) argued the "stress-vulnerability model of addiction" (p. 200) proposes that chronic stress will lead people to search for ways to cope with their stress, and this inevitably leads to a reduction of willpower, more risk-taking, and an increased likelihood of addiction. Chronic stress has been implicated in elevated susceptibility to numerous kinds of addictions due to changes in the brain's motivational pathways (e.g., the PFC), which influences people's self-control. Thus, prolonged stress may change a person's ability to self-regulate, resulting in greater susceptibility to addiction when a new source of stress is encountered. Self-control is often times related to chronic stress and addiction, and the experimenters noted that: "self-control pathways may be susceptible to individual adaptations to stress that may alter physiological response and reward sensitivity when future stress is encountered" (p. 201). In other words, after experiencing chronic stress, the parts of the brain responsible for self-control and avoiding impulsive responding may become less efficient at inhibiting impulsive behavior. This may lead to increased risk of drug use, including cigarette smoking. Ansell et al. found evidence to support the hypothesis that 
prolonged exposure to stressors increased the risk of smoking by increasing impulsivity, among other processes.

To further investigate the relationship between stress and nicotine dependence in college students, Balke, Lynskey, and Agrawal (2009) used a large sample $(N=18,013)$ of current smokers. Participants were asked to rate how many stressful events they had experienced over the past year, (e.g., occupational, familial, financial, and legal issues). Participants were also assessed for nicotine dependence, based on the DSM-IV criteria, and were considered dependent on nicotine if they answered in the affirmative to three or more of these criteria. Stressful life events were positively related to nicotine dependence, with the following events associated with nicotine dependence: "moving/having someone move in, unemployment/job searching for over a month, change of jobs, job responsibilities, work orders, separation, divorce, a breakup from a steady relationship, financial crisis, bankruptcy, insolvency, and imprisonment/trouble with the law with a family member" (p. 86). This study provides further evidence that stressors may contribute to substance use, in this case nicotine dependence.

Alcohol and tobacco are often used together (e.g., Piasecki et al., 2007). Weitzman and Chen (2005) noted that close to $98 \%$ of college students who smoked cigarettes also drank alcohol. For college freshman, students who started smoking cigarettes prior to beginning college had a higher incidence of binge drinking compared to students who did not begin smoking until they reached college (Saules et al., 2004). Reed, Wang, Shillington, Clapp, and Lange, (2007) examined the association between cigarette and alcohol use in a group of undergraduate university students. To test this 
relationship, the authors categorized the students based upon their smoking history, which included never smoked, experimenters who smoked occasionally, and current smokers. Compared to non-smokers, experimental smokers and current smokers consumed more alcohol each time they drank in the preceding 28 days. These findings illustrate the strength of the correlation between cigarette and alcohol use and how pervasive drinking is for even for casual smokers.

Similarly, Witkiewitz et al. (2005) examined the relationship between smoking cigarettes and drinking alcohol. To do so, subjects were given access for 21 days to an electronic diary to record their daily use of cigarettes and alcohol. The authors found that $4 \%$ of respondents stated they smoked and drank daily, $51 \%$ claimed they drank while smoking several instances per-week, and 44\% maintained they smoked cigarettes while drinking a minimum of once a week. In addition, Witkiewitz et al. noted that smoking was reported for $44 \%$ of all drinking events, and those smokers who identified themselves as being daily smokers also reported drinking and smoking during the same instance $60 \%$ of the time. The mean number of alcoholic beverages consumed was higher for smokers than for non-smokers, while the mean number of cigarettes smoked while drinking was three times higher than when not drinking. Witkiewitz et al. also noted the biggest contextual factors for smoking while drinking included being outdoors, being with other smokers, and being at a place where it is considered acceptable to smoke cigarettes. Stress also appeared to lead to smoking while drinking. In addition, the researchers maintained for individuals who were addicted to smoking cigarettes and were attempting to quit, using alcohol was shown to be a factor in resuming the habit, and 
consuming alcohol was linked with an increased desire to smoke. The authors argued this may be due in part because alcohol is often a prompt to smoke. It has also been postulated alcohol and cigarettes may be cues for each other, by activating the same dopaminergic pathway, leading to a desire for both.

Because of the prevalence of the alcohol-cigarette drug combination, the cooccurrence of cigarette and alcohol use has garnered considerable attention. Piaseki et al. (2011) noted that disorders related to alcohol consumption share a strong relationship with heavy cigarette use, and the likelihood of being a current smoker is tied into how many DSM criteria for an alcohol disorder are met by an individual. To further the investigation of this association, the researchers used an ecological momentary assessment (EM), which relies upon participants using a diary to record their "assessments of immediate states and behaviors that are collected while respondents inhabit their natural environment" (p. 558). Participants included in the study were classified as current drinkers if they reported drinking at least four drinks in the last month, with more self-reported current smokers than non-smokers. Participants completed measures of nicotine and alcohol dependence. Participants were given a diary to use for 21 consecutive days, in which they recorded their daily alcohol and cigarette use, along with a series of questions regarding their use of both substances. There was a significant positive relationship between cigarette and alcohol consumption. Not surprisingly, respondents reported enjoying their cigarette use more when they were drinking, took more pleasure from their cigarette use when they also consumed alcohol, and reported when they did drink, they enjoyed the first drink the most. Thus, the two 
substances enhanced the subjective pleasure obtained from each other. These results again highlight the strength of the connection between these two substances, especially in college-aged young adults. This must not be overlooked when planning ways to reduce or eliminate the use of the drugs in this population.

\section{Gender Differences in Stress, Alcohol Use, and Cigarette Smoking}

For college students, stress seems to be a large part of the college experience and for some, stress can become debilitating if left unchecked. For this reason, Brougham et al. (2009) investigated possible differences between male and female college students in their stress levels. Several different sources of stress were assessed, including those stemming from school (e.g., studying for an exam), finances (e.g., spending too much), social relationships (e.g., a difficult breakup), family problems (e.g., an illness in the family), and daily events. Participants rated how stressful each category was for them. Females had significantly higher overall perceived levels of stress than did males. The researchers noted that females also reported having more family stress and exhibited more stress with regard to financial issues and daily occurrences. Females also reported having experienced more stress resulting from interpersonal relationships than did men. Other studies have found similar results (e.g., McIntire, Korn, \& Matsuo, 2008). These results illustrate the notion women tend to have higher stress levels than do men, and programs designed to reduce stress should be sensitive to the differences in the types of stressors that affect men and women differently.

Such self-report data are critical in designing effective prevention and treatment programs because university personnel may have a misunderstanding with respect to the 
types of stressors that affect their students. For example, Misra, McKean, West, and Russo (2000) explored the link between gender and stress, while also investigating faculty members' views of their students' stress levels. Full-time students answered questions about "five categories of academic stressors (frustration, conflicts, pressure, changes, and self imposed)" and "four categories describing reactions to stressors (psychological, emotional, behavior, and cognitive)" (p. 237). A parallel version of the survey was used for the faculty members. There was a considerable difference between students self-reported stress levels and stressors and the faculty members' ideas about their students levels of stress. The faculty claimed their students were more stressed out, and exhibited more responses (behavioral, emotional, and physiological) to stress than what students told researchers. The authors postulated that the faculty members' perception of students stress levels may stem from the fact that they only interact with them in class, where students stress levels may be higher than being somewhere comfortable (e.g., home). Mirsa et al. also noted women indicated having higher stress levels and reported more stressors than did men. Women students also reported having experienced more adverse life events and more self-imposed stress (e.g., competition with others) when compared to men. The authors explained that this gender difference in stress may be due, in part, to women students' increased demands in terms of school, work, and home life.

As we have seen, much of the relevant research has shown that women have higher stress levels than do men. Eaton and Bradley (2008) noted that there are several contrasting opinions as to why this is so. The differential exposure hypothesis argues that 
some individuals are simply exposed to more stress-inducing stimuli, while the differential vulnerability hypothesis states some people are more vulnerable to stressors. The authors noted this vulnerability stems from "differences in appraisals of stressors, reactivity to stressors, choice of coping strategies, and effectiveness of coping strategy use" (p. 95), and there may be gender differences in terms of strategies. Men are more apt to take their problems head on (e.g., seek problem-focused strategies), whereas women tend to use more emotional coping styles (e.g., social support), and this difference in strategies may help explain gender differences in perceive stress. Eaton and Bradley noted a third strategy, known as avoidance coping, which involves such strategies as denying the problem exists or avoiding it all together. To test the association between perceived stress, coping strategies, and potential gender differences Eaton and Bradley used four standardized written scenarios, one of which was about a "close friend," another about work, a third involving an "important relationship," and the last about an exam. Researchers asked women and men (mean age $=23$ years) to rate how stressful each scene made them feel, using the nine-item Tension-Anxiety subscale from the Profile of Mood States inventory. The authors noted that coping in the sample was measured by using the six subscales of the 12-item Coping Orientation to Problems Experienced inventory. Women described the scenes as being more stressful than did men, and the researchers argued this lends support to the idea of the differential vulnerability theory (i.e., females are more susceptible to stress). Females used all three coping strategies more than did men, but they used the emotion-focused strategy the most frequently. In contrast, men were more likely to used problem-focused coping strategy. 
The researchers suggested that the gender differences in coping strategies may come from a lifetime of gender socialization, with men being taught to face their problems head on and women being taught to seek out others to help them deal with their problems.

Researchers have examined gender differences with respect to alcohol consumption. For example, Wilsnack, R. W., Wilsnack, S. C., Kristjanson, VolgeltanzHolm, and Gmel (2009) analyzed the relationship between gender and alcohol consumption using information from 35 separate countries including the United States. The total amount of alcohol imbibed in the course of a year, along with the average number of drinks consumed when alcohol was ingested were measured. Males were significantly more likely to be current drinkers when compared to females, and females were more likely to have reported being "lifetime abstainers." In addition, men were more likely to have consumed alcohol over a 12-month period, were more prone to drink alcohol on five or more days a week, and were more likely to report binge drinking (five or more drinks on a single occasion). These findings confirm other studies that have demonstrated that compared to women men drink more alcohol, drink more often, and consume more when they drink.

To better understand this gender difference in drinking behavior, de Vissar and McDonell (2012) examined the double standards of alcohol use in college students. The authors suggested that differences in gender roles play a key part in how people view drinking alcohol, which subsequently influences their drinking patterns. Binge drinking has been associated with a host of negative outcomes such as accidents, and violence, with men in the U.S. known to binge drink more than females. de Vissar and McDonell 
noted this pattern of binge drinking increases males' risk for adverse outcomes. The researchers argued the Western concept of what is to be feminine and masculine are most often seen as sitting on opposite sides of the spectrum, and a person's actions are directly tied to these ideas of how men and women should act. In the US, attitudes such as masculine men can drink more than those who are not is a good example of a gender role that might encourage drinking. However, the researchers noted this does not hold true for women, because oftentimes binge drinking in females is linked with promiscuity, and is therefore unbecoming of a lady. The media also plays into these stereotypes by targeting men in beer ads, and women for wine and spirits. The authors employed a mixed-method approach using a quantitative survey designed to assess gender differences and relationships between gender roles and identity, along with qualitative interviews. The experimenters used a sample of students who reported having stereotypical or equal views of gender roles. The authors asked these students "Do gender double-standards exist for alcohol use persist among university students?”, "Do gender double-standards for alcohol reflect broader gender role attitudes?", and "How do young people experience gender double-standards for alcohol use?". The authors also administered a survey to assess attitudes and behaviors regarding male and female stereotypes, and alcohol use. Both genders, but particularly females, expressed attitudes towards drinking that were consistent with a "desired gender identity." Consuming beer, drinking large amounts per sitting, and being drunk in public were all associated with masculinity. Even those students who claimed to view gender in the most equitable ways stated it is not lady-like for women to drink too much. Finally, the authors pointed out despite the fact that most 
students recognized the unjustness of these double standards, the idea that women's and men's drinking are judged differently was still widely held.

With respect to gender differences in cigarette use, Morrell, Cohen, Bacchia, and West (2005) surveyed college students on their cigarette use. Morell et al. pointed out that young adults are especially at risk for smoking, with $45 \%$ of all cigarette users being between the ages of 18 and 25 years. The authors administered a web-based survey that assessed current and previous cigarette use. Two-thirds of the students claimed they had tried smoking cigarettes at least once in their lifetime, and 37\% reported they currently smoke. For women, 66\% stated they had tried smoking at least once in their lifetime, and $40 \%$ reported they currently smoked. For men, $68 \%$ reported smoking at least once in their lifetime, and $38 \%$ claimed to be current smokers. Female gender was a significant predictor for status as a "lifetime smoker," and this finding shows how prevalent smoking is for female students.

Moskal, Dziuban, and West (1999) argued college students are at an elevated risk for picking up harmful habits (e.g., smoking), which could become lifetime patterns, partly because of their transition from adolescence to adulthood. The researchers pointed out roughly 400,000 people a year die as a result of smoking, with 61,000 women dying from heart complications in 1990 alone, and is the most frequently reported reason of preventable death. To investigate this, the experimenters gave the Health Risk Behaviors Survey for University Students, which measures risky behavior and substance use to a sample of students from throughout the Florida's state university system. The results of the statewide survey pointed out females (39\%) were significantly more likely than men 
(22\%) to be everyday smokers, and although not significant, women (46\%) more often claimed they were trying to quit smoking when contrasted with men (45\%). The authors maintained the US spends an average of 80 billion dollars per year due to health care costs and reduced work efficiency, and despite the mounting evidence against cigarette use, smoking on college campuses is persists and must be addressed.

Harris, Schwartz, and Thompson (2008) explored the connection between gender and smoking in college students and to what extent they wanted to quit. To assess smoking status, researchers asked participants "Do you consider yourself a regular smoker?". If the subjects answered yes, they were also asked when they would stop smoking and how much did they desired to quit. Younger females (freshman and sophomores) were significantly more likely to be self-reported regular smokers than were similarly aged males. Nearly $40 \%$ of respondents stated they smoked more cigarettes since entering college, compared to $31 \%$ who claimed they had lessened their use. In addition, the researchers noted that women were significantly more likely to report "wanting to quit very much," and wanting to stop before they finished their education. The researchers suggested that programs designed to help students quit smoking should focus on younger female college students.

A substantial body of work confirms that female college students smoke more than do their male counterparts (e.g., Harris et al., 2008). However, less is known about gender differences in reactions to smoking cues. Saladin et al. (2012) investigated smoking cues and their association to stress-inducing stimuli and craving, defined as "a subjective state that refers to an internal experience of desire" (p. 211). The researchers 
used a sample containing adult females and males, all of whom were in good health other than describing themselves as being addicted to nicotine. The experimenters provided four different stimulus cues that included: "An in vivo smoking cue; An in vivo neutral cue; An imagery-based script consisting of negative affect/stress cue; and An imagerybased control script consisting of neutral/relaxing imagery" (p. 211). Smokers in the "smoking in vivo condition" were asked to pick up and remove a cigarette from a pack of their favorite brand and smell it, whereas those in the "neutral in vivo cue" condition simply held a pack of pencils. Participants exposed to the "negative affect/stress script" were asked before the study to describe an event in their lives that had caused them great stress, and the researchers used this to create a 75-second audio file to play back to them. Finally, the "neutral/relaxing script" protocol subjected smokers to a 75-second audio clip of a neutral event they had reported prior to the start of the study. Desire to smoke was measured using the Questionnaire of Smoking Urges-Brief (QSU-B), which asked respondents to rate how much they wanted to smoke. Perceived stress levels were assessed using the Self-Assessment Manikin (SAM), which asks participants to report how much stress they were feeling. Women reported feeling a greater desire to smoke following the smoking cue and rated the stressful scenes as being more stress inducing than did the men. The authors argued the results from their study highlights the problem female smoker's face in terms of stress, and women may be especially vulnerable when attempting to stop smoking. Female's problems with stress and smoking may stem from getting into the habit of smoking after experiencing an uncomfortable mood or stressor, which reinforces smoking behaviors. Finally, the researchers maintained for women 
trying to stop their use of cigarettes it may be doubly hard if they having troubles with their partner who is also a smoker, particularly if they live together, because the partner will provide regular smoking cues. Again, these finding illustrate the importance of smoking cessation programs, which specifically target females.

Stress in combination with cigarette and alcohol use, can present considerable obstacles for college students to handle and overcome. In terms of stress, small-tomoderate amounts can prompt individuals to perform at higher levels than they would without it. Large amounts of stress, however, can be quite debilitating. If left unchecked, stress can lead to problems with drinking and smoking, in an attempt to cope with negative emotions. In addition, this literature review revealed an association between drinking and smoking: Smoking cigarettes increased the likelihood of consuming alcohol (Witkiewitz et al., 2012). The review of the literature regarding gender differences indicated women tend to feel more stressed than men (Brougham et al., 2009), and are more likely to smoke compared to men (Morrell et al., 2005). With respect to alcohol consumption, men tend to consume more alcohol and in larger quantities than do than women (Wilsnack et al., 2009).

Much research has been conducted examining the possible link between stress and substance use in college students. For college administrators, general data on trends in college students might be helpful, but it is not always clear the extent to which data from published studies generalize to specific campuses. Given that many studies have used relatively homogeneous samples (e.g., those containing mostly White students), the results of these studies may not provide sufficient information for more diverse 
campuses. Therefore, data from specific college campuses are needed: (a) to determine if substance use and stress pose a problem for their students, and, if so, (b) to design effective education and intervention programs tailored to the characteristics of students on those campuses. To that end, the present study examined the relationships among stress, cigarette smoking, alcohol consumption, and gender using data collected by the San José State University Student Health Center (SJSU SHC). The instrument used to collect data was the American College Health Association's National College Health Assessment II (NCHA-II), a nationally administered questionnaire.

\section{Research Hypotheses}

This study tested the following hypotheses:

1. Stress will be positively correlated with alcohol use.

2. Stress will be positively correlated with cigarette use.

3. Cigarette use and alcohol use will be positively correlated.

4. Female students will report higher levels of stress than male students.

5. Female students will smoke more than male students.

6. Male students will drink more than female students.

\section{Method}

\section{Participants}

Participants were SJSU students. The original data collection was conducted online from a random sample of SJSU students. From the initial sample, 2,260 student responses were obtained. Table 1 describes the demographic characteristics of the students who responded. Approval was obtained from the SJSU Institutional Review 
Board (IRB) and the Registrar's office prior to the questionnaire being dispersed to the participants via emails. Included in the Appendix is a sample of the email asking participants to complete the questionnaire, along with information regarding possible incentives for participants (e.g., iTunes gift cards). Participants were also sent two emails reminding them to complete the questionnaire. Lastly, to help endorse the study, a flyer was created and circulated throughout campus at SJSU. The present archival study was also approved by the SJSU IRB.

\section{Materials}

This study analyzed the data from the American College Health Association's National College Health Assessment II (NCHA-II). This questionnaire was designed to assess information regarding college students' health-related behaviors, such as drug use, unsafe sex, nutrition, and so on. For this study, the following variables were examined: reported alcohol use, tobacco use, stress levels, and gender. The ACHA noted the NCHA-II was developed and designed using the initial NCHA as its model, which has been shown to have solid reliability and validity. The ACHA conducted a principal component analysis to decide whether clusters of items in the NCHA-II were associated with each other. They did so by comparing groups of items from a sample taken in the spring of 2009 with that of one from the spring of 2010. The authors maintained any alpha coefficient over 70 is thought to be a solid association. The results of this analysis indicated the Standardized Alpha coefficient for the group of items entitled, Moderately Used Drugs, which included the questions on the frequency of alcohol and cigarette use in the past 30 days was .74 for both spring of 2009 and 2010. In addition, the authors 
found the Alpha coefficients for the individual item asking participants how often they have used alcohol in the past 30 days to be .67 for the spring of 2009 and 2010. Also, the individual item asking how often during the preceding 30 days the participant has used cigarettes was .66 for both the spring of 2009 and 2010. The perceived stress question was grouped into the Academic-Interpersonal Difficulties cluster and the Standardized Alpha coefficient was .79 for both the spring of 2009 and 2010. The individual Alpha coefficient for the perceived stress item was .73 for the spring of 2009 and 2010 .

To further test the reliability and validity of the NCHA-II, researchers contrasted a series of important sections from the NCHA with a set of "nationally representative databases" (ACHA, 2011) (p. 6), such as the National College Health Risk Behavior Survey (Center for Disease Control, 1995 \& the Harvard School of Public Health, 1999). These researchers also ran item reliability analyses, to distinguish intersecting items between these databases. In addition, experimenters conducted a construct validity analysis, contrasting ACHA-NCHA research findings with these databases. The experimenters also carried out measurement validity analysis, comparing findings from the ACHA-NCHA with the same group of databases. In order to compare any possible differences between the NCHA and the NCHA-II, the ACHA first made use of students from eight different colleges $(N=8,458)$ in the US, and did so again with students from another seven colleges $(N=7,681)$ a year later. The results of this comparison found only small and insignificant differences between the two measures. 
Table 1.

Student Demographic Information

\begin{tabular}{lrr}
\hline Category & $\boldsymbol{n}$ & $\boldsymbol{\%}$ \\
\hline Gender & 1,265 & 56 \\
\hline Female & 949 & 42 \\
Male & 2 & $<1$ \\
Transgender & & 16 \\
\hline Year in school & 362 & 10 \\
\hline $1^{\text {st }}$ year undergraduate & 226 & 20 \\
$2^{\text {nd }}$ year undergraduate & 452 & 18 \\
$3^{\text {rd }}$ year undergraduate & 407 & 15 \\
$4^{\text {th }}$ year undergraduate & 339 & 18 \\
$5^{\text {th }}$ year undergraduate or more & 407 & 87 \\
Graduate or professional & & 12 \\
\hline Enrollment status & 1,966 & \\
\hline Full-time students & 271 & 36 \\
Part-time students & & 6 \\
\hline Race/Ethnicity & 814 & 34 \\
\hline White & 768 & 17 \\
Black/African American & 384 & 44 \\
Hispanic/Latin & 994 & \\
Asian/Pacific Islander & 23 & \\
American Indian/Alaskan & 90 & \\
Biracial/Multiracial & & \\
Other & & \\
\hline & & \\
\hline
\end{tabular}

Note: All values are rounded to the nearest whole number.

Variables and Analyses

Alcohol use was measured using the question, "Within the last thirty days, in how many days did you use alcohol? (1) Never used (2) Have used, but not in the last 30 (3) 1-2 days (4) 3-5 days (5) 6-9 days (6) 10- 19 days (7) 20-29 days (8) Used daily." This variable was dichotomized such that participants who reported 1 or 2 were placed in the 
category "Not used in the last 30 days" and the rest of the participants were placed in the category "Used in the last 30 days." Cigarette use was measured using the question, "Within the last thirty days, in how many days did you use cigarettes? (1) Never used (2) Have used but not in the last 30 (3) 1-2 days (4) 3-5 days (5) 6-9 days (6) 10-19 days (7) 20-29 days (8) Used daily." Cigarette use was dichotomized in the same way as alcohol use. Perceived stress was measured using the question: "Within the last 12 months, how would you rate your overall level of stress you have experienced? (1) No stress (2) Less than average stress (3) Average stress (4) More than average stress (5) Tremendous stress." Perceived stress was dichotomized such that participants who reported 1-3 were placed in the category "No to average stress" and the rest of the participants were placed in the category "Above average stress." Gender was measured using the question: "What is your gender? (1) Female; (2) Male; (3) Transgender." Due to the very small number of individuals identifying themselves as transgender, we did not include these individuals in any analysis. Because the variables of interest are categorical in nature, 2 × 2 chi-square tests of independence were used to analyze the relationships between pairs of variables. For all tests, alpha was set to .05. Descriptive statistics and chi-square tests were computed using SPSS v. 20 (IBM< Inc.). Odds ratios and associated confidence intervals were computed using an online calculator (http://vassarstats.net/odds2x2.html).

\section{Results}

Table 2 displays the results of the chi-square analyses and phi coefficients for all relationships. Tables 3-8 display the frequencies and percentages (within columns) for 
the variables included in the chi-square analyses in the order in which they appear in Table 1.

Table 2.

Results of Chi-square Analyses

\begin{tabular}{lcrr}
\hline Variables & Phi & Chi-square & $p$ \\
\hline Stress/Alcohol use & .11 & 28.60 & $<.0001$ \\
Stress/Cigarette use & .03 & 2.08 & .15 \\
Cigarette/Alcohol use & .25 & 137.83 & $<.0001$ \\
Gender/Stress & -.13 & 34.68 & $<.0001$ \\
Gender/Alcohol use & -.01 & .16 & .69 \\
Gender/Cigarette use & .08 & 15.41 & $<.0001$ \\
\hline
\end{tabular}

Note. Bold $p$-values indicate that the relationship was significant at the .05 level.

There was a significant relationship between perceived stress and alcohol use, $\chi^{2}(1, N=$ $2,216)=28.60, p<.0001, O R=1.58(95 \% \mathrm{CI}=1.34,1.87)$. Students who reported above average stress were over 1.58 times more likely to report drinking alcohol in the past 30 days than those who reported no to average stress. An additional chi-square goodness-of-fit test showed that participants who reported having consumed alcohol at least once in the past 30 days were significantly more likely to report having aboveaverage stress, $\chi^{2}(1, N=1,220)=5.25, p=.02$. These results support our first hypothesis. 
Table 3.

Perceived Stress by Alcohol Use

\begin{tabular}{lrrrrrrr}
\hline & \multicolumn{3}{c}{ Alcohol Use } & & & \\
\hline Perceived Stress Levels & Not used & $\%$ & Used & $\%$ & Total & $\%$ \\
\cline { 2 - 8 } No to Average Stress & 579 & 58 & 570 & 47 & 1,149 & 52 \\
Above Average Stress & 417 & 42 & 650 & 53 & 1,067 & 48 \\
\hline Total & 992 & 52 & 1,220 & 48 & 2,216 & 100 \\
\hline
\end{tabular}

Our second hypothesis was not supported, as the relationship between stress and cigarette use was not significant, $\chi^{2}(1, N=2,216)=2.08, p=.15, O R=1.22(95 \% \mathrm{CI}=$ $0.93,1.61)$. Students who were more stressed were not more likely to smoke cigarettes in the last 30 days.

Table 4.

Perceived Stress by Cigarette Use

\begin{tabular}{lrrrrrr}
\hline & \multicolumn{3}{c}{ Cigarette Use } & & & \\
\hline Perceived Stress Levels & Not used & $\%$ & Used & $\%$ & Total & $\%$ \\
\cline { 2 - 8 } No to Average Stress & 1,045 & 52 & 107 & 47 & 1,152 & 52 \\
Above Average Stress & 949 & 48 & 119 & 53 & 1,068 & 48 \\
& & & & & & \\
\hline Total & 1,994 & 90 & 226 & 10 & 2,220 & 100 \\
\hline
\end{tabular}

There was a significant overall relationship between cigarette and alcohol use. Participants who reported using alcohol at least once in the past 30 days were significantly more likely to have smoked at least once in the past 30 days as well, $\chi^{2}(1, N$ $=2,233)=137.83, p<.0001, O R=11.07(95 \% \mathrm{CI}=6.79,18.07)$. Thus, students who 
smoked were about 11 times more likely to drink alcohol. These data support our third hypothesis.

Table 5.

Cigarette Use by Alcohol Use

\begin{tabular}{lrrrrrr}
\hline & \multicolumn{7}{c}{ Alcohol Use } & & & \\
\hline Cigarette Use & Not used & $\%$ & Used & $\%$ & Total & $\%$ \\
\cline { 2 - 7 } Not Used & 985 & 98 & 1,023 & 83 & 2,008 & 90 \\
Used & 18 & 2 & 207 & 17 & 225 & 10 \\
& & & & & & \\
\hline Total & 1,003 & 45 & 1,230 & 55 & 2,233 & 100 \\
\hline
\end{tabular}

The overall association between gender and stress was also significant. The results of the goodness-of-fit test showed females were more likely to report feeling above average-stress levels when compared to men, $\chi^{2}(1, N=2,208)=34.68, p<.0001$, $O R=1.67(95 \% \mathrm{CI}=1.40,1.98)$. Women were 1.67 times more likely than men to report above average stress. These data support our fourth hypothesis.

Table 6.

Gender by Perceived Stress

\begin{tabular}{lrrrrrrr}
\hline \multirow{2}{*}{ Gender } & \multicolumn{7}{c}{ Perceived Stress Levels } \\
Female & $\begin{array}{c}\text { No to } \\
\text { Average } \\
\text { Stress }\end{array}$ & $\begin{array}{r}\text { Above } \\
\text { Average } \\
\text { Stress }\end{array}$ & $\%$ & Total & $\%$ \\
\cline { 2 - 8 } Male & 585 & 51 & 674 & 63 & 1,259 & 57 \\
& 561 & 49 & 388 & 37 & 949 & 43 \\
\hline Total & 1,146 & 52 & 1,062 & 48 & 2,208 & 100 \\
\hline
\end{tabular}


The data showed no overall association between gender and alcohol use, $\chi^{2}(1, N=$ $2,208)=0.16, p=.69, O R=1.04(95 \% \mathrm{CI}=0.87,1.23)$. However, significantly more women than men reported alcohol use in the past 30 days, $\chi^{2}(1, N=2,208)=26.65, p<$ .0001. These data contradict our hypothesis.

Table 7.

Gender by Alcohol Use

\begin{tabular}{|c|c|c|c|c|c|c|}
\hline \multicolumn{7}{|c|}{ Alcohol Use } \\
\hline Gender & Not used & $\%$ & Used & $\%$ & Total & $\%$ \\
\hline Female & 561 & 57 & 698 & 57 & 1,259 & 57 \\
\hline Male & 431 & 43 & 518 & 43 & 949 & 43 \\
\hline Total & 992 & 45 & 1,216 & 55 & 2,208 & 100 \\
\hline
\end{tabular}

However, there was an overall significant relationship between gender and cigarette use, with more women reporting that they have used cigarettes in the last 30 days when compared to men, $\chi^{2}(1, \mathrm{~N}=2,214)=15.41, p<.0001, O R=0.58(95 \% \mathrm{CI}=0.44,0.76)$. Women were about half as likely to have smoked cigarettes in the last 30 days. These data contradict our sixth hypothesis.

Table 8.

Gender by Cigarette Use

\begin{tabular}{lrrrrrrr}
\hline & \multicolumn{7}{c}{ Cigarette Use } \\
Gender & Not used & $\%$ & Used & $\%$ & Total & $\%$ \\
Female & 1,161 & 57 & 100 & 57 & 1,259 & 57 \\
\cline { 2 - 8 } Male & 829 & 43 & 124 & 43 & 949 & 43 \\
& & & & & & & \\
\hline Total & 992 & 45 & 1,216 & 55 & 2,208 & 100 \\
\hline
\end{tabular}




\section{Discussion}

A great deal of research has been conducted investigating the potential relationship between stress and substance use in college students (e.g., O’Hare \& Sherrer, 2006). The aim of the current study was to examine the relationships among stress, alcohol use, cigarette smoking, and gender in a large, diverse sample of SJSU students. Although previous research has investigated these variables in college students, it is possible that the results of those studies may not adequately capture the events occurring at any particular university, especially those, like SJSU, that are very diverse. We feel that the information from our study can be useful to university administrators by providing explicit data about their students. These data can then be used to guide and inform education and intervention programs that are tailored to SJSU students.

In terms of stress and alcohol consumption, participants who reported having low levels of stress were less likely to have used alcohol in the last 30 days compared to students who reported having high amounts of stress. These findings are consistent with our hypothesis that there would be a positive relationship between stress and alcohol. This finding is also consistent with past research (e.g., Keys et al., 2011; Rutledge \& Sher, 2001) and highlights the importance of the link between stress and alcohol use. Although our data are correlational, making causal inferences difficult, it is possible that students in our sample use alcohol as a means to cope with stress (Becker et al., 2011; Park et al., 2004). Many college students experience frequent, and sometimes intense, stress (Brougham et al., 2009), and those who use alcohol to cope may be at higher risk of abusing alcohol than those who use other coping strategies. 
Contrary to our hypothesis, no significant relationship between stress and cigarette use was found. This finding is not surprising given the contradictory results reported in the literature. For example, as we noted before, Naquin and Gilbert (1996) found that stress was positively correlated with smoking in college students, and Balke et al. (2009) reported that many stressful life events were positively associated with nicotine dependence. In laboratory studies, Perkins and Grobe (1992) found that exposure to acute stressors increase self-reported desire to smoke, and Perkins et al. (1992) found smoking reduces subjective feelings of stress. Childs and de Wit (2010) reported that an acute stressor increased participants' reported desire to smoke, but did not reliably increase the number of cigarettes smoked in the entire sample. In subsets of smokers, however, the stressor did increase smoking and/or subjective pleasure from smoking. Participants who reported engaging in consistent patterns of smoking describe smoking as being more pleasurable after being exposed to a stressor. For participants who reported stronger urges to smoke to relieve withdrawal and craving, the stressor experienced more pleasure from smoking and smoked more. Some researchers, using naturalistic methods, have found that stress is not a strong predictor of smoking in college students (Cronk \& Piasecki, 2010; Piasecki et al., 2007), particularly when controlling for other drug use (Magid et al., 2009). The findings with respect to the relationship between stress and smoking behavior (as opposed to self-reported desire to smoke) are mixed and deserve additional scrutiny. Perhaps the findings of Childs and de Wit, that there are subsets of smokers who may be more likely to smoke following exposure to stress. Future research should seek to distinguish subsets of smokers based on their smoking 
habits, motives for smoking, and sensitivity to the influence of environmental events on their smoking behavior.

With regard to cigarette and alcohol use, participants who smoked were more likely to have used alcohol. These data support our hypothesis that these two variables would be positively correlated. These results are consistent with those of past studies that have shown a similar relationship between these two forms of drug use (e.g., Dieker et al., 2006; Piasecki et al., 2011; Reed et al., 2007; Weitzman \& Chen, 2005; Witkiewitz et al., 2005). For many smokers, using alcohol and smoking cigarettes are behaviors that co-occur in a social context (Witkiewitz et al., 2005), and the two drugs may prompt the use of each other (Reed et al., 2007) and enhance the subjective pleasure obtained from using them. Even smoking infrequently can have damaging physiological effects, and its strong ties to alcohol use suggest that interventions to reduce smoking should also target co-occurring alcohol use.

As we hypothesized, women were more likely than were men to report feelings of above-average stress. This is also consistent with past research indicating women tend to feel more stressed than men (Brougham et al., 2009; Day \& Livingstone, 2003; McIntire et al., 2008). It seems as if women are at a unique risk for being susceptible to stress and its effects. Our study did not investigate gender differences in the types of stressors and their relationship to stress levels, but other studies have done so. For example, Brougham et al. found that women were significantly more likely to report being stressed by family issues, finances, and daily occurrences. Mirsa et al. (2000) found that women were also reported more stressors than did men and were more prone to self-imposed stress (e.g., 
being stressed from competition with others). Eaton and Bradley (2008) reported that women and men generally use different coping strategies. Men tend to use problemfocused strategies, whereas women were more likely to use emotional coping styles. Given that women consistently report more stress, it is possible that they are more vulnerable to stress and/or that their coping strategies are ineffective at protecting them from stress (of course, other possible factors may play a role). Regardless, from these results, it is clear that gender differences exist in the level of perceived stress, as well as the types of stressors and coping styles used to handle stress. Therefore, stress-reduction programs should use this information to tailor their interventions to the unique situations faced by women compared to those faced by men.

Contrary to our hypothesis, we found no gender differences in self-reported drinking in the last 30 days. These data are inconsistent with those from past work, which has consistently found that men drink more, on average, than do women (e.g., Holmilia \& Raitasalo, 2005; Wilsnack et al., 2009). One possible explanation for this discrepancy is the way that we coded alcohol use. For convenience, and to ensure we had enough participants in each category, we placed all students who reported drinking at least once in the last 30 days were categorized as alcohol users. All other students were categorized as non-users. It is possible that this categorization scheme reduced variability among the different levels of drinking, thereby obscuring a relationship between gender and alcohol use. An alcohol-use variable with more categories might have been more sensitive to gender differences in alcohol use. Despite the lack of significant relationship 
between gender and alcohol use, over half of our sample reported drinking in the last 30 days.

Given that alcohol consumption is a key health concern for students, their families, and the university, more research on the drinking habits of SJSU students would be beneficial.

As we hypothesized, women also were significantly more likely to have used cigarettes in the recent past compared to men. This finding is consistent with past research that has repeatedly found that women tend to smoke more than men (e.g., Harris et al., 2008; Morrell et al., 2005; Moskal et al., 1999), and that women are more vulnerable to the effects of stress on smoking. For example, Saladin et al. (2012) found that women reported stress-inducing cues more stressful than did men and reported a greater desire to smoke than did men after exposure to a stress cue. Thus, stressreduction programs for women might include a smoking cessation intervention as part of a treatment package. Such a treatment package could teach and encourage healthy alternatives to smoking in response to stressors.

When interpreting the results of the present study, the reader should consider a few limitations. First, it is possible that this study suffers from non-response and selection biases, given that (a) not all students who were contacted provided their data, and (b) those who did respond selected themselves into the study. Therefore, those who did not respond may be different in important ways from our participants, making our sample less representative of all SJSU students. Nevertheless, our sample comprised over $7 \%$ of the student body, and the demographic characteristics of our participants are 
similar to the university as a whole, although women (56\% vs. 52\%) and White students (36\% vs. 26\%) tended to be overrepresented. Even so, these data provide useful information with respect to the behaviors and experiences of a substantial number of our students. With no alternative means of obtaining similar data from our students, the data in this study represent the best "snapshot" of health-related behaviors that we have available. Two other limitations that we mentioned previously are that (a) the data come from an observational design, so this limits the extent to which we can make causal statements about the relationships we observed; and (b) our coding procedures might have obscured important differences in the behaviors we examined. In addition, the sample characteristics may have changed since the data was collected in 2012. Despite these limitations, there were several strengths to the study. First, the current study had a large sample size, which was roughly $7 \%$ of the entire SJSU population. Second, this study used the NCHA-II, which is a nationally recognized, standardized questionnaire. It has been rigorously tested and has been shown to have solid reliability and validity. Third, many of our findings were consistent with those of other studies, which provided evidence for the external validity of our results.

The current study showed a strong link between stress and alcohol use, and, going forward administrators would do well to focus on effective and efficient ways to reduce college students stress levels, particularly in freshmen who are susceptible to high stress stemming from the adjustment to college life (Bland et al., 2012). In some individuals, these large amounts of stress can lead to the overuse of alcohol. Females seem particularly vulnerable to stress, and this can lead to a heightened risk of cigarette use. 
Additional studies are needed to delineate better ways to help colleges reduce their alcohol and cigarette consumption, because college students are prone to drink frequently and the ties between smoking and drinking are well established. Here at SJSU, students who are feeling stressed about academics or personal issues have access to the Student Health Center, which has a programmable massage chair that can be used by students at no charge. SJSU also has a staff of mental health professionals who provide discreet services, including personal and crisis counseling to help students overcome barriers to achieving their academic goals. Many students are not aware of these services, and a better effort is required to educate students on the resources at their disposal on campus.

Even if students are educated about on-campus resources, it is likely that many will not use these resources due to a variety of reasons, including scheduling problems, fear, or the stigma associated with seeking help. One way to overcome some of these problems is to provide web- and peer-based resources that help students monitor and change their behavior for the better. College students today are using technology more and more, and the presence of peers can reduce some of the stigma and anxiety associated with seeking help. Chiauzzi, Brevard, Thurn, Decembrele, and Lord (2008) created an online stress management course at six US colleges, with all students between the ages of 18-24. It was designed to help college students adopt a healthy approach to dealing with stress. Entitled MyStudentBody-Stress, the program used unique feedback for each individual by having respondent's complete five different online questionnaires, which assessed students' stress levels, mood, coping skills, and daily hassles. This information was then used to provide the student with targeted information on how to handle their 
stress. Students who participated in the curriculum "were more likely to increase weekly physical activity, use specific stress management methods, and exhibit decreased anxiety and family problems" (Bervard et al., 2008, p. 555). Because there is often stigma surrounding seeing a counselor or therapist, and doing so may be inconvenient due to scheduling conflicts, this program allows students to benefit from the counseling in the safety of their own home. Given that these online programs are likely to be relatively cost-effective and are available 24 hours a day, other colleges and universities might consider developing similar online programs. This seems even more important when funding for higher education is being reduced.

With respect to drug use, the concept of harm reduction has begun to gain momentum. Logan and Marlott (2010) defined harm reduction as "an umbrella term for interventions aiming to reduce problematic effects of behavior" (p. 201). Many harmreduction programs focus on lessening college students drinking. For example, the Alcohol Skills Training Program (ASTP) puts students together in groups and makes use of cognitive-behavioral training. Students clarify drinking norms and use motivational interviews, which are designed to improve student's desire to reduce their alcohol use (Logan \& Marlott, 2010). The authors noted this intervention has been shown to reduce alcohol use in students and exhibits solid generalizability to a broad range of ethnicities. The Brief Alcohol Screening and Intervention for College Students (BASICS) also uses motivational interviewing, but does so with only one student at a time (Logan \& Marlott, 2010). The researchers pointed this program only uses one to two session with the student, but has shown positive results. Harm-reduction approaches have the benefit of 
teaching new skills rather than focusing on simply punishing drug-using behavior without teaching appropriate behaviors to replace it.

Incoming freshman have a great deal of changes taking place in their lives. Often times they must leave their homes and settle into a new social and academic environment, and these changes make them at risk for drug use, including cigarette smoking.

Obermayer, Riley, Asif, and Jean-Mary (2004) developed a six-week text- and web-based intervention to help college students quit smoking. The researchers noted that the intervention was developed using a website where students could report information about their smoking habits and complete the Nicotine-Dependence Syndrome Scale. The website provided feedback about how many cigarettes a day students were smoking so they could track their progress. The authors noted participants were reminded via text messages when their chosen date to quit was, and the messages became more frequent as the day approached. In addition, students were asked to find a support buddy, who was encouraged to text them positive statements regarding their quitting throughout the study (Obermayer et al., 2004). At the end of the six-weeks the authors noted that 10 of the 27 participants included in the final analysis stopped smoking entirely, and another 20 attempted to quit for one day. In addition, the average amount of cigarettes smoked per week was cut in more than half. These findings are very encouraging in the fight to help student smoker quit for good and shows evidence that behavioral monitoring and social support can be of great assistance in helping students to do just that. In addition to developing web-, text-, and peer-based programs to teach appropriate stress-management techniques and reduce the harm caused by alcohol and cigarette use, we recommend that 
universities require some type of class or information session directly pertaining to these behavioral health issues. Also, programs that aim to increase a student's social support network with peers who do not use alcohol, cigarettes, or other drugs would be useful. Providing social support for students has been consistently shown to alleviate stress in individuals (Ursin \& Erikson, 2003), and creating a healthy social network can be a powerful tool in helping students adjust to their new lives, without relying on substance use to cope or socialize. 


\section{References}

American College Health Association. American College Health Association-National College Health Assessment II: Reliability and Validity Analyses 2012. Hanover, MD: American College Health Association; 2012.

Andreano, J, M., Cahill, L. (2006). Glucocorticoid Release and Memory Consolidation in Men and Women. Psychological Science, 17(6), 466-470. doi:

10.1111/j.1467/9280.2006.01729.x

Ansel, E. B., Gu, P., Tuit, K., \& Sinha, R. (2012). Effects of cumulative stress and impulsivity on smoking status. Human Psychopharmacology: Clinical \& Experimental, 27(2), 200-208. doi:10.1002/hup.1269

Balke, E., Lynskey, M. T., \& Argawal, A. (2009). The Association Between DSM-IV Nicotine Dependence and Stressful Life Events in the National Epidemiologic Survey on Alcohol and Related Conditions. American Journal Of Drug And Alcohol Abuse, 35(2), 85-90.

Bandura, A. (1982). Self-efficacy mechanism in human agency. American psychologist, $37(2), 122$

Beck, R. C. (2004). Motivation: Theories And Principles ( $5^{\text {th }}$ Ed.). Upper Saddle River, NJ: Pearson Education.

Becker, H., Lopez, M., \& Doremus-Fitzwater, T. (2011). Effects of stress on alcohol drinking: a review of animal studies. Psychopharmacology, 218(1), 131-156.

Bland, H. W., Melton, B. F., Welle, P., \& Bingham, L. (2012). Stress tolerance: New challenges for millennial college students. College Student Journal, 46(2), 362275.

Bourgham, R., Zail, C., Mendoza, C., Miller, J. (2009). Stress, Sex Differences, and Coping Strategies Among College Students. Current Psychology, 28(2), 85-97. doi:10.1007/s12144-009-

Buwalda, B., Scholte, J., de Boer, S. F., Coppens, C. M., \& Koolhaas, J. M. (2012). The acute glucocorticoid stress response does not differentiate between rewarding and aversive social stimuli in rats. Hormones and behavior, 61(2), 218226. 
Chakravarty S, Reddy BR, Sudhakar SR, Saxena S, Das T, et al. (2013) Chronic Unpredictable Stress (CUS)-Induced Anxiety and Related Mood Disorders in A Zebra Fish Model: Altered Brain Proteome Profile Implicates Mitochondrial Dysfunction. PLoS ONE 8(5): e63302. doi:10.1371/journal.pone.0063302

Charmandari, E., Tsigos, C., \& Chrousos, G. (2005). Endocrinology of the stress response 1. Annual Review of Physiology, 67, 259-284.

Chiazzu, E., Brevard, J., Thurn, C., Decembrele, S., \& Lord, S. (2008). MyStudentBodyStress: An Online Stress Management Intervention For College Students. Journal of Health Communication, 13(6), 555-572. doi:10.1080/10810730802281668

Childs, E., \& DeWit, H. (2009). Hormonal, cardiovascular, and subjective responses to acute stress in smokers. Psychopharmacology, 203(1), 1-12. doi:10.1007/s00213008-1359-5

Cronk, N. J., \& Piasecki, T. M. (2010). Contextual and subjective antecedents of smoking in a college student sample. Nicotine \& Tobacco Research, 12(10), 997-1004.

Day, A. L., \& Livingstone, H. A. (2003). Gender differences in perceptions of stressors and utilization of social support among university students. Canadian Journal of Behavioral Science, 35, 73-83.

Dayas, C. V., Buller, K. M., Crane, J.W., Xu, Y. Y., \& Day, T. A. (2001). Stressor categorization: Acute physical and psychological stressor elicits distinctive recruitment patterns in the amygdala and in medullary norandrenic cell groups. European Journal Of Neuroscience, 14(7), 1143-1152. doi:10.1046/j.0953816x.2001.01733.x

de Visser, R, O., \& McDonnell, E. J., (2012). 'That's OK. He's a guy': A mixed-method study of gender double standards for alcohol use. Psychology \& Health, 27(5), 618-639. doi:10.1080/08870446.2011..617444

Dickerson, S. S., \& Kemeny, M. E. (2004). Acute stressors and cortisol responses: a theoretical integration and synthesis of laboratory research. Psychological bulletin, 130(3), 355.

Dierker, L., Lloyd-Richardson, E., Stolar, M., Flay, B., Tiffany, S., Collins, L., The Tobacco Etiology Research Network. (2006). The proximal association between smoking and alcohol use among first year college students. Drug and Alcohol Dependence, 81, 1-9. doi:10.1016/j.drugalcdep.2005.05.012 
Eaton, R. J., \& Bradley, G. (2008). The role of gender and negative affectivity in stressor appraisal and coping selection. International Journal of Stress Management, 15(1), 94-115.

Elliot, B.M., Faraday, M. M., Grunberg, N. E. (2003). Repeated acute stress alters heart morphometry. Stress: The International Journal On The Biology Of Stress, 6(1), 63-70. doi: 10.1080/1025389021000053344

Engelbrecht, A., Smith, C., Neethling, I., Thomas, M., Ellis, B., Matheyse, M., \& Myburgh., K. H. (2010). Daily brief restraint stress alters signaling pathways and induces atrophy and apoptosis in rat skeletal muscle. Stress: The International Journal On The Biology Of Stress, 13(2) 132-141. doi:10.3109/10253890903089834

Ferreira, M., \& Willoughby, D. (2007). Alcohol consumption: the good, the bad, the indifferent. Applied Physiology, Nutrition \& Metabolism, 33(1), 12-20.

Gaab, J. J., Rohleder, N. N., Nater, U. M., \& Ehlert, U. U. (2005). Psychological determinants of the cortisol stress response: The role of anticipatory cognitive appraisal. Psyhconeuroendocrinology, 30(6), 599-601.

doi:10.1016/j.psyneuen.2005.02.001

Harris, J, B., Schwartz, S, M., \& Thompon, B. (2008). Characteristics associated with self-identification as a regular smoker and desire to quit among college students who smoke cigarettes. Nicotine \& Tobacco Research, 10(1), 69-76. doi:10.1080/14622200701704202

Hayes, B., Curry, J., Freeman, M. S., \& Kuch, T. H. (2010). A Counseling Model for Alcohol Abuse in College: A case study. Journal Of College Counseling, 13(1), 87-96.

Herman, J. P. (2012). Neural pathways of stress integration: Relevance to alcohol abuse. Alcohol Research: Current Reviews, 34(4), 441-447.

Herman, J. P., \& Cullinan, W. E. (1997). Neurocircuitry of stress: central control of the hypothalamo-pituitary-adrenocortical axis. Trends in neurosciences, 20(2), 7884.

Herman, J. P., Ostrander, M. M., Mueller, N. K., \& Figueiredo, H. (2005). Limbic system mechanisms of stress regulation: hypothalamo-pituitary-adrenocortical axis. Progress in Neuro-Psychopharmacology and Biological Psychiatry, 29(8), 12011213. 
Homilia, M., \& Raitasalo, K. (2005). Gender differences in drinking: Why do they still exist? Addiction, 100(12), 1763-1769.

Hughes, B. M., (2005). Study, examinations and stress: blood pressure assessments in college students. Educational Review, 57(1), 21-36.

doi:10.1080/0013191042000274169

Johnston, L.D., O’Malley, P.M., \& Bachman, J.G. (2003). Monitoring the Future national survey results on drug use, 1975-2002. Volume II: College students and adults ages 19-40 (NIH Publication No. 03-5376). Bethesda, MD: National Institute on Drug Abuse. Retrieved March 27, 2014 from http://monitoringthefuture.org/pubs/monographs/vol2_2002.pdf

Kelly, J. L., LaVergne, D, D., Boon, H, r., \& Boon, D. A. (2012). Perceptions of college students on social factors that influence matriculation. College Student Journal, 46(3), 653-664.

Keys, K. M., \& Hatzenbuehler, M. L., Hasin, D. S., (2011). Stressful life experiences, alcohol consumption, and alcohol use disorders: The epidemiologic evidence for four main types of stressors. Psychopharmacology, 218(1), 1-17. doi:1007/s00213-011-2236-1

Koolhaas, J. M., Bartolomucci, A., Buwalda, B., De Boer, S. F., Flügge, G., Korte, S. M., et al. (2011). Stress revisited: a critical evaluation of the stress concept. Neuroscience \& Biobehavioral Reviews, 35(5), 1291-1301.

Kudielka, B. M., \& Kirschbaum, C. (2005). Sex differences in HPA axis responses to stress: a review. Biological psychology, 69(1), 113-132.

Le Houezec, J., McNeill, A., \& Britton, J. (2011). Tobacco, nicotine and harm reduction. Drug And Alcohol Review, 30(2), 199-123. doi:10.1111/j.14653362.2010.00264.x

Logan, D, E., \& Marlatt, G. (2010). Harm reduction therapy: A practice-friendly review of research. Journal Of Clinical Psychology, 66(2), 201-214.

Lufty, K., Brown, M. C., Nerio, N., Aimiuwu, O., Tran, B., Anghel, A., \& Friedman, T. C. (2006). Repeated stress alters nicotine's ability to activate the hypothalamicpituitary-adrenal axis. Journal of Neurochemistry, 99(5), 1321-1327. doi:10.1111/j.1471-4159.200604217.x 
Magid, V., Colder, C. R., Stroud, L. R., Nichter, M., \& Nichter, M. (2009). Negative affect, stress, and smoking in college students: unique associations independent of alcohol and marijuana use. Addictive behaviors, 34(11), 973-975.

May, R. W., \& Casazza, S. P., (2012). Academic major as a perceived stress indicator: Extending stress management intervention. College Student Journal, 46(2), 264273.

May, R. W., \& Kyle, B. (2007). Perceived stress as a function of academic major. Poster session presentation at the Southeastern Psychological Association Conference, New Orleans, LA.

McEwen, B. S. (2000). The neurobiology of stress: from serendipity to clinical relevance. Brain research, 886(1), 172-189.

McIntire, K. P., Korn, J. H., \& Matsuo, H. (2008). Sweating the small stuff: How different types of hassles result in the experience of stress. Stress and Health: Journal Of The International Society For The Investigation Of Stress, 24(5), 383392.

Misra, R., McKean, M., West, S., \& Russo, T. (2000). Academic stress of college students: Comparison of Student and faculty perceptions. College Student Journal, 34(2), 236-245.

Morrell, H. R., Cohen, L. N., Bacchi, D., \& West, J. (2005). Predictors of smoking and smokeless tobacco use in college students: A preliminary study using web-based survey methodology. Journal of American College Health, 54(2), 108-115. Doi:10.3200/JACH.54.2.108-115

Moskal, P. D., Dziuban, C. D., \& West, G. B. (1999). Examining the use of tobacco on college campuses. Journal Of American College Health, 47(6), 260-265.

Naquin, M. R., \& Gilbert, G. G. (1996). College students' smoking behavior, perceived stress, and coping styles. Journal of Drug Education, 26(4), 367-376.

Nelson, M. C., Lust, K., Story, M., \& Ehlinger, E. (2008). Credit Card Debt, Stress and Key Risk Behaviors Among College Students. American Journal of Health Promotion, 22(6), 400-407.

Obermayer, J. L., Riley, W. T., Asif, O., \& Jean-Mary, J. (2004). College Smoking Cessation Using Cell-Phone Text Messaging. Journal Of American College Health, 53(2), 71-78. doi:10.3200/JACH.53.2.71-78 
O'Hare, T., \& Sherrer, M. V., (2006). Stress, recent changes in alcohol consumption level, and problem drinking in freshmen first Offenders. Journal of Human Behavior in the Social Environment, 13(3), 33-50. doi:10.1300/J137v13n0303

O'Malley, P. M. \& Johnston, L. D. (2002).Epidemiology of alcohol and other drug use among American college students. Journal of Studies on Alcohol, Supplement No. 14, 23-39.

Patterson, F., Lerman, C., Kaufmann, V. G., Neuner, G. A., \& Audrain-McGovern, J. (2004). Cigarette smoking practices among American college students: review and future directions. Journal of American College Health, 52(5), 203-212.

Park, C. L., Armeli, S., \& Tennen, H. (2004). The daily stress and coping process and alcohol use among college students. Journal of Studies on Alcohol and Drugs, 65(1), 126

Perkins, K. A., \& Grobe, J. E. (1992). Increased desire to smoke during acute stress. British journal of addiction, 87(7), 1037-1040.

Perkins, K. A., Grobe, J. E., Fonte, C., \& Breus, M. (1992). "Paradoxical” effects of smoking on subjective stress versus cardiovascular arousal in males and females. Pharmacology Biochemistry and Behavior, 42(2), 301-311.

Piasecki, T. M., Jahng, S., Wood, P. K., Robertson, B. M., Epler, A. J., Cronk, N, J., \&...Sher, K. J. (2011). The subjective effects of alcohol-tobacco co-use: An ecological momentary assessment investigation. Journal Of Abnormal Psychology, 120(3), 557-571. doi:10.1037/a0023033

Piasecki, T. M., Richardson, A. E., \& Smith, S. M. (2007). Self-monitored motives for smoking among college students. Psychology of Addictive Behaviors, 21(3), 328.

Porcu, P., Sogliano, C., Cinus, M., Purdy, R. H., Biggio, G., \& Concas, A. (2003). Nicotine-induced changes in cerebrocortical neuroactive steroids and plasma corticosterone concentrations in the rat. Pharmacology, Biochemistry \& Behavior, 74(3) 683-690. doi:10.1016/S0091-3057(02)01065-1

Raio, C. M., Orederu, T. A., Palazzalo, L., Shurick, A. A., \& Phelps, E. A., (2013). Cognitive emotion regulation fails the stress test. PNAS Proceedings Of The National Academy Of Sciences Of The United States Of America, 110(37), 1513915144. doi:10.1073/pnas.1305706110 
Reed, M. B., Wang, R., Shillington, A. M., Clapp, J. D., \& Lange, J. E. (2007). The relationship between alcohol use and cigarette smoking in a sample of undergraduate college students. Addictive Behaviors, 32(3) 449-464. doi:10.1016/j.addbeh.2006.05.016

Read, J. P., Wood, M. D., Kahler, C. W., Maddock, J. E., \& Palfai, T. P. (2003). Examining the role of drinking motives in college student alcohol use and problems. Psychology of Addictive Behaviors, 17(1), 13.

Rutledge, P C. \& Sher, K. J. (2001). Heavy drinking from the freshman year into early young adulthood: The roles of stress, tension-reduction drinking motives, gender and personality. Journal of Studies on Alcohol, 62(4), 457-466.

Saladin, M. E., Grey, K. M., Carpenter, M. J., LaRowe, S. D., DeSantis, S. M., \& Upadhyaya, H. P. (2012). Gender differences in craving and cue reactivity to smoking and negative affect/stress cues. The American Journal Of Addictions, 21(3), 210-220. dio:10.1111/j.1521-0391.2012.00232.x

Selye, H. (1936). A syndrome produced by diverse nocuous agents. Nature, $138(3479), 32$.

Selye, H. (1950). Stress and the general adaptation syndrome. British Medical Journal, 1(4667), 1383.

Sinha R. (2008). Chronic stress, drug use, and vulnerability to addiction. Annals Of The New York Academy Of Science, 1141105-130. doi:10.1196/annals.1441.030

Smith SM, Vale WW (2006). The role of the hypothalamic-pituitary adrenal axis in neuroendocrine responses to stress. Dialogues in Clinical Neuroscience 8(4) 383395

Steptoe, A., \& Ussher, M. (2006). Smoking, cortisol and nicotine. International Journal Of Psychophysiology 59(3), 228-235. doi:10.1016/ijpsycho.2005.10.011

Ulrich-Lai, Y. M., \& Herman, J. P. (2009). Neural regulation of endocrine and autonomic stress responses. Nature Reviews Neuroscience, 10(6), 397-409.

Ursin, H., \& Eriksen, H. R. (2004). The cognitive activation theory of stress. Psychoneuroendocrinology, 29(5), 567-592. 
Weitzman, E. R., \& Chen, Y. Y. (2005). The co-occurrence of smoking and drinking among young adults in college: National survey results from the United States. Drug and Alcohol Dependence, 80(3), 377-386. doi:10.1016/j.drugalcdep.2005.05.008

Wilsnack, R. W., Wilsnack, S. C., Kristjanson, A. F., Vogeltanz-Holm, N. D.,\& Gmel, G. (2009). Gender and alcohol consumption: Patterns from the Multinational GENACIS project. Addiction, 104(9), 1487-1500. doi:10.1111/j.13600443.2009.02696.x

Witkiewitz, K., Desai, S. A., Steckler, G., Jackson, K. M., Bowen, S., Leigh., B. C., \& Larimer M. E. (2005). Concurrent drinking and smoking among college students: An event level analysis. Psychology of addictive behaviors, 26(3), 649-654. doi: $10.1037 / \mathrm{a} 0025363$ 


\section{Appendix A}

Letter to students asking for their participation and possible compensation Dear Participant,

You have been randomly selected to be part of important research that is being conducted by the Wellness and Health Promotion Department of the Student Health Center that will benefit all San José State University students.

The National College Health Assessment is a survey designed to assess student health behaviors and is conducted by the American College Health Association (ACHA). We value your feedback and we will use it to help us provide better services and support for

you. As an added bonus, once you have completed the survey you will get the chance to win one of our great prizes. Once you have completed the survey you will be automatically entered in the drawing to win one of the following: 1 Kindle Fire, 1 Wii, 1 iBeats Headphones with ControlTalk From Monster®, 20 iTunes cards valued at \$25 each, or 5 iPod shuffles.

Your participation in this survey is completely voluntary and confidential. All data and identifying information will be stored in a secure server by the American College Health Association. No SJSU staff will be able to link your name or email address to your answers. We encourage you to complete the survey in one sitting, which typically takes about 20-30 minutes. Some of the survey questions may be considered personal or sensitive in nature. If you feel any discomfort, please be advised that you are free to decline to answer questions or withdraw at any time. Refusing or withdrawing will involve no penalty or loss of benefits. 
If you are 18 years or older and agree to participate, please click on the following internet address to continue:

If you have any questions or concerns about this survey, you may contact the Assistant Director for Campus Wellness, Laurie Morgan at laurie.morgan@ @jsu.edu or visit http://www.sjsu.edu/studenthealth/ to access a list of health resources that may be of assistance.

Your cooperation is greatly appreciated.

Thank you,

Wellness and Health Promotion Department

San José State University Health Center 


\section{Appendix B}

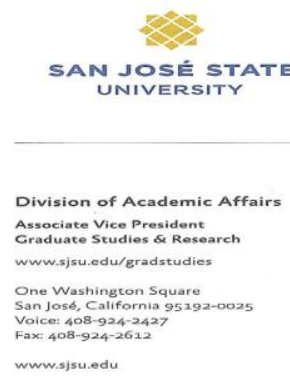

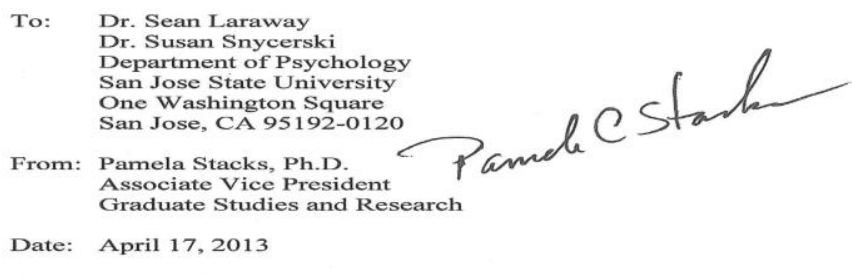

The Human Subjects-Institutional Review Board has registered your study entitled:

"An Analysis of SJSU Student Responses on The American College Health Association - National College Health Assessment II (ACHA-NCHA II)"

This registration, which provides exempt status under Exemption Category 4 of SJSU Policy SO8-7, is contingent upon the subjects included in your research project being appropriately protected from risk.

Specifically, protection of the anonymity of the subjects' identity with regard to all data that may be collected about the subjects from you to be ensured.

This registration includes continued monitoring of your research by the Board to assure that the subjects are being adequately and properly protected from such risks. If at any time a subject becomes injured or immediately. Injury includes but is not limited to bodily harm,

psychological trauma, and release of potentially damaging personal

information. This approval for the human subject's portion of your project is in effect for one year, and data collection beyond April 17, 2014 requires an extension request.

If you have any questions, please contact me at (408) 924-2427.

Protocol \#: F1302075

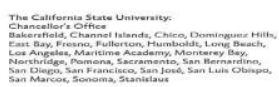

